\title{
Serum Lipoprotein (a) Levels in Chronic Renal Failure and Liver Cirrhosis Patients. Relationship with Atherosclerosis
}

\author{
Essam Mady,2,\#, Gehane Wissal, \\ Ali Khalifa ${ }^{2}$ and Mahmoud El-Sabbagh ${ }^{1}$ \\ ${ }^{1}$ Department of Biochemistry, Faculty of \\ Science, Ain Shams University, Cairo, Egypt \\ ${ }^{2}$ Oncology Diagnostic Unit, Department of \\ Biochemistry, Faculty of Medicine, Ain \\ Shams University, Abbassia, Cairo, Egypt
}

\begin{abstract}
This study was carried out to investigate the relationship between lipoprotein (a) levels and the development of atherosclerosis in chronic renal failure (CRF) patients with the possible role of the liver. Serum Lp (a) levels were measured in samples from $20 \mathrm{CRF}$ patients on hemodialysis (HD), 20 liver cirrhosis (LC) patients, 20 patients having both CRF and LC and undergoing HD, and 20 normal control subjects. Renal function (blood urea nitrogen (BUN) and creatinine), hepatic function (transaminases (ALT and AST), alkaline phosphatase (ALP) and total bilirubin) investigations and serum cholesterol were carried out for all the subjects enrolled in this study. Serum Lp (a) concentration in CRF patients without LC was $87.25 \pm 6.17 \mathrm{mg} / \mathrm{dl}$, which was significantly higher than all the investigated groups $(\mathrm{P}<0.001)$. Lp(a) concentration in patients with both $\mathrm{CRF}$ and LC was $24.65 \pm 1.98$ $\mathrm{mg} / \mathrm{dl}$, which was not significantly different from the controls, but was significantly higher than that in the subjects with LC only $(\mathrm{P}<0.001)$ where the latter group had significantly low Lp (a) values $(11.1 \pm 0.99)$ relative to all the other groups (P<0.001). Lp (a) correlated positively with cholesterol in all groups except the LC subjects, but did not correlate with age, or renal function in both CRF groups.
\end{abstract}

\footnotetext{
\# Present Address: Faculty of Education, King Faisal University, P.O. Box 1759, Al-Hassa 31982, Saudi Arabia.
}

KEYWORDS: Lipoprotein (a), cholesterol, chronic renal failure, liver cirrhosis, atherosclerosis

\section{INTRODUCTION}

Patients with chronic renal insufficiency and end-stage renal disease (ESRD) form a group with a well-known high incidence of cardiovascular diseases [1,2]. Lipid metabolism abnormalities play a large role in the progression of renal diseases. Patients with ESRD suffer from an increased incidence of atherosclerotic diseases [2-4].

Increased lipoprotein $(\operatorname{Lp}(a))$ levels may be the earliest and more consistent lipid alteration seen in predialysis renal failure patients. Several studies confirmed $L p(a)$ to be a risk factor for atherosclerosis alterations in end-stage renal disease (ESRD) independent of alterations in other lipid parameters. Plasma Lp(a) increases and attains maximal levels with mild/moderate reduction in renal function, and does not seem to change through late renal failure stage, or in relation to the introduction of hemodialysis [511]. $L p(a)$ is synthesized primarily, if not entirely in the liver. It constitutes a macromolecular complex in human plasma contained in LDL and consisting of an apoB-100 molecule and an apo(a) molecule linked together by a disulfide bond. Lp(a) plasma level is normally genetically determined and remains constant throughout adult life. An arbitrary normal upper limit of $30 \mathrm{mg} / \mathrm{dl}$ has been proposed for $\mathrm{Lp}(\mathrm{a})$ above which the risk for premature coronary heart diseases (CHD) increases [12-15].

$\mathrm{Lp}$ (a) levels in ESRD patients may reach 3-4 times higher levels than in normal subjects $[2,18]$ 
independent of apo(a) isoform, which could be due to decreased Lp(a) catabolism, by the kidney and/or increased hepatic synthesis of apo(a). $\mathrm{Lp}$ (a) has been considered to be more strongly related to the risk of CHD than HDL-C and LDL$\mathrm{C}$, and independent of the other known risk factors. $\mathrm{Lp}$ (a) particles appear to bind preferentially to the arterial vessel wall. They may act synergistically with apolipoprotein B to promote atherosclerosis $[1,3,4,12]$.

The present study aimed to investigate the effects of the functional state of kidney and liver, both individually and in combination, on the $\mathrm{Lp}$ (a) levels in CRF and/or LC patients with special emphasis on their association with the development and/or regression of atherosclerosis diseases associated with CRF.

\section{SUBJECTS AND METHODS}

\section{Subjects}

$60 \mathrm{CRF}$ and LC adult male patients were chosen from the dialysis unit and internal medicine department at Ain Shams University Hospital in Cairo, along with 20 healthy normal control subjects. The patients were divided into three groups, each consisting of 20 subjects, CRF patients group, LC patients group, and patients having both CRF and LC. They were thoroughly investigated and their clinical examination confirmed that they suffered only from CRF and/or LC. Duration of these disorders was five to seven years before carrying out this study. Patients with CRF have been undergoing hemodialysis for four hours, twice a week and on the basis of extensive clinical assessment, they were further subdivided into atherosclerotic and non-atherosclerotic subgroups. None of the CRF patients with LC was atherosclerotic. The mean age (mean \pm SE) of CRF group was $51.95 \pm 1.66$ years, LC group was $52.05 \pm 2.08$ years, CRF with LC group was $52.40 \pm 1.40$ years and for the normal controls was $50 \pm 2.22$ years.

\section{Methods}

Fasting serum samples were used for this study. For the hemodialysis patients, blood samples were withdrawn just before starting dialysis. The renal function, hepatic function, and cholesterol assays were performed using Synchron CX5 Clinical System (Beckman, USA). Lp(a) was assayed immunologically [19] by enzyme-linked immunosorbent assay (ELISA) (Innogenetics, Belgium). The results were analyzed using SPSS package (Echo Soft Corp., USA, 1993). Analysis of variance (ANOVA) was applied to demonstrate the diagnostic value of the assayed parameters in the studied disorders.

Table 1

Statistical analysis of the results of the lipid parameters and age in the main investigated groups

\begin{tabular}{|c|c|c|c|c|c|c|c|}
\hline & $\mathrm{C}$ & $\mathrm{CRF}$ & $\mathrm{LC}$ & $\mathrm{CRF} / \mathrm{LC}$ & $\begin{array}{l}\text { CRF \& } \\
\text { LC }\end{array}$ & $\begin{array}{l}\text { CRF \& } \\
\text { CRF/LC }\end{array}$ & $\begin{array}{l}\text { LC \& } \\
\text { CRF/LC }\end{array}$ \\
\hline \multicolumn{8}{|l|}{ Cholesterol (mg/dL) } \\
\hline $\mathrm{t}$ & & -2.65 & 9.47 & 10.64 & 8.96 & -9.69 & -0.76 \\
\hline$P$ & & $<0.01$ & $<0.001$ & $<0.001$ & $<0.001$ & $<0.001$ & $>0.05$ \\
\hline \multicolumn{8}{|l|}{$\mathrm{Lp}(\mathrm{a})(\mathrm{mg} / \mathrm{dL})$} \\
\hline mean \pm S.E. & $25.25 \pm 2.0$ & $87.25 \pm 6.17$ & $11.10 \pm 0.99$ & $24.65 \pm 1.98$ & & & \\
\hline $\mathrm{t}$ & & -9.56 & 6.35 & 0.21 & 12.18 & -9.66 & 6.12 \\
\hline$P$ & & $<0.001$ & $<0.001$ & $>0.05$ & $<0.001$ & $<0.001$ & $<0.001$ \\
\hline \multicolumn{8}{|l|}{ Age (years) } \\
\hline mean \pm S.E. & $50.0 \pm 2.22$ & $52.05 \pm 2.08$ & $52.40 \pm 1.40$ & $51.95 \pm 1.66$ & & & \\
\hline $\begin{array}{l}\mathrm{t} \\
P\end{array}$ & & $\begin{array}{l}-0.67 \\
>0.05\end{array}$ & $\begin{array}{l}-0.91 \\
>0.05\end{array}$ & $\begin{array}{l}-0.70 \\
>0.05\end{array}$ & $\begin{array}{l}-0.14 \\
>0.05\end{array}$ & $\begin{array}{l}-0.04 \\
>0.05\end{array}$ & $\begin{array}{l}-0.21 \\
>0.05\end{array}$ \\
\hline
\end{tabular}


Table 2

Statistical analysis of the results of the CRF subgroups

\begin{tabular}{lllc}
\hline & $\begin{array}{l}\text { Subgroup A (non-atherosclerotic) } \\
\mathrm{n}=10\end{array}$ & $\begin{array}{l}\text { Subgroup B (atherosclerotic) } \\
\mathrm{n}=10\end{array}$ & $\mathrm{t}$ \\
& mean \pm S.E. & mean \pm S.E. & $>0.05$ \\
\hline BUN (mg/dL) & $86.20 \pm 12.59$ & $86.70 \pm 10.64$ & -0.03 \\
Creatinine (mg/dL) & $12.90 \pm 1.16$ & $12.60 \pm 0.76$ & 0.21 \\
ALT (IU/L) & $11.80 \pm 0.88$ & $11.80 \pm 0.99$ & 0.08 \\
AST (IU/L) & $13.40 \pm 1.28$ & $14.90 \pm 1.19$ & -0.85 \\
ALP (IU/L) & $106.70 \pm 5.95$ & $106.20 \pm 8.43$ & $>0.05$ \\
T. Bilirubin (mg/dL) & $0.66 \pm 0.09$ & $0.49 \pm 0.07$ & $>0.04$ \\
Cholesterol (mg/dL) & $207.60 \pm 5.88$ & $276.30 \pm 9.92$ & $>05$ \\
Lp(a) (mg/dL) & $65.90 \pm 6.44$ & $108.60 \pm 4.26$ & $>0.05$ \\
Age (years) & $47.10 \pm 1.44$ & $57.0 \pm 3.27$ & -5.95 \\
\hline
\end{tabular}

\section{RESULTS}

Cholesterol. The CRF subjects without LC had significantly higher cholesterol levels than the controls $(\mathrm{P}<0.01)$ and the other patients' groups $(\mathrm{P}<0.001)$ (Table 1). On the other hand, the CRF subjects who had LC and the LC patients had significantly lower levels than the control $(\mathrm{P}<0.001)$, but non-significantly different from each other $(\mathrm{P}>0.05)$. In this study, $50 \%$ of the CRF subjects without LC were atherosclerotic having significantly higher cholesterol levels than their non-atherosclerotic counterparts $(\mathrm{P}<0.001)$ (Table 2). A significant positive correlation was found between cholesterol and age in all the patients' groups (in CRF subjects with LC, $\mathrm{r}=0.49448$; in CRF subjects without LC, $r=0.54223$ (Fig. 1) and in LC subjects, $r=0.41482)$.

Lipoprotein $(a)$. Wide variations were observed in Lp(a) levels among the patients' groups when compared with the controls. The CRF subjects without LC had significantly elevated Lp(a) levels $(\mathrm{P}<0.001)$ (Table 1), while the CRF subjects with LC showed no significant change $(\mathrm{P}>0.05)$, and the LC patients had significantly reduced levels $(\mathrm{P}<0.001)$. Consequently, Lp(a) levels were significantly different among the three patients' groups $(\mathrm{P}<0.001)$. Also, the atherosclerotic CRF subjects had significantly elevated levels compared with the non-atherosclerotic subjects $(\mathrm{P}<0.001)$ (Table 2). In the CRF subjects without LC, no correlation was found between
Lp(a) and either age, BUN or creatinine $(r=0.2834, \quad r=0.27765$ and $r=0.10057$ respectively). However, a positive correlation was found between Lp(a) and cholesterol (Fig 2) in this group $(\mathrm{r}=0.6878)$ and in the CRF subjects with LC $(r=0.68778)$ although $\mathrm{Lp}(\mathrm{a})$ did not correlate to age in the latter group $(\mathrm{r}=0.08305)$. On the other hand, no correlation was found between $\mathrm{Lp}(\mathrm{a})$ and either cholesterol $(r=0.34979)$ or age $(r=0.31623)$ in the LC subjects.

Renal function. The CRF patients, both with and without LC, showed significantly elevated BUN and creatinine levels compared with the controls $(\mathrm{P}<0.001)$ (Table 3), with no significant difference between the atherosclerotic and nonatherosclerotic subjects $(\mathrm{P}>0.05)$ (Table 2). The LC patients showed significantly decreased BUN levels compared with the controls, and consequently, with the other investigated patients' groups $(\mathrm{P}<0.001)$, but showed nonsignificantly different creatinine levels from those of the controls $(\mathrm{P}>0.05)$, but significantly lower than those of the CRF patients with and without LC $(\mathrm{P}<0.001)$. The CRF patients who also had LC had significantly lower BUN and creatinine levels than those without LC $(\mathrm{P}<0.01$ and $\mathrm{P}<0.001$ respectively).

Hepatic function. The transaminases (ALT and AST), total bilirubin levels and ALP showed significant elevations in the CRF subjects who had also LC, and in the LC patients compared with both the controls and the CRF subjects who did not have LC $(\mathrm{P}<0.001)$ (Table 3$)$. This 
Table 3

Statistical analyses of the results of the kidney and liver functions in the main investigated groups

\begin{tabular}{|c|c|c|c|c|c|c|c|}
\hline & $\mathrm{C}$ & $\mathrm{CRF} / \mathrm{LC}$ & CRF & $\mathrm{LC}$ & $\begin{array}{l}\text { CRF/LC } \\
\& \text { CRF }\end{array}$ & $\begin{array}{l}\text { CRF/LC } \\
\& \text { LC }\end{array}$ & $\begin{array}{l}\text { CRF \& } \\
\text { LC }\end{array}$ \\
\hline \multicolumn{8}{|l|}{ BUN (mg/dL) } \\
\hline mean \pm S.E. & $13.90 \pm 0.71$ & $58.80 \pm 5.30$ & $86.45 \pm 8.02$ & $10.0 \pm 0.51$ & & & \\
\hline $\mathrm{t}$ & & -8.39 & -9.01 & 4.47 & -2.88 & 9.16 & 9.51 \\
\hline$P$ & & $<0.001$ & $<0.001$ & $<0.001$ & $<0.01$ & $<0.001$ & $<0.001$ \\
\hline \multicolumn{8}{|c|}{ Creatinine (mg/dL) } \\
\hline mean \pm S.E. & $0.70 \pm 0.07$ & $9.30 \pm 0.54$ & $12.75 \pm 0.68$ & $0.73 \pm 0.07$ & & & \\
\hline $\mathrm{t}$ & & -15.72 & -17.75 & -0.49 & -3.98 & 15.58 & 17.63 \\
\hline$P$ & & $<0.001$ & $<0.001$ & $>0.05$ & $<0.001$ & $<0.001$ & $<0.001$ \\
\hline \multicolumn{8}{|l|}{ ALT (IU/L) } \\
\hline mean \pm S.E. & $10.90 \pm 0.79$ & $51.15 \pm 3.39$ & $11.80 \pm 0.64$ & $35.20 \pm 2.77$ & & & \\
\hline $\mathrm{t}$ & & -15.17 & -1.13 & -11.11 & 16.92 & 3.83 & -11.47 \\
\hline$P$ & & $<0.001$ & $>0.05$ & $<0.001$ & $<0.001$ & $<0.001$ & $<0.001$ \\
\hline \multicolumn{8}{|l|}{ AST (IU/L) } \\
\hline mean \pm S.E. & $13.15 \pm 0.83$ & $62.65 \pm 4.20$ & $14.15 \pm 0.87$ & $50.58 \pm 4.16$ & & & \\
\hline $\mathrm{t}$ & & -11.56 & -0.83 & -8.90 & 11.30 & 2.0 & -8.65 \\
\hline$P$ & & $<0.001$ & $>0.05$ & $<0.001$ & $<0.001$ & $<0.05$ & $<0.001$ \\
\hline \multicolumn{8}{|l|}{ ALP (IU/L) } \\
\hline mean \pm S.E. & $65.10 \pm 3.86$ & $143.05 \pm 5.11$ & $106.45 \pm 5.03$ & $115.75 \pm 7.53$ & & & \\
\hline $\mathrm{t}$ & & -12.17 & -6.53 & -6.10 & 5.11 & 3.05 & -1.04 \\
\hline$P$ & & $<0.001$ & $<0.001$ & $<0.001$ & $<0.001$ & $<0.01$ & $<0.001$ \\
\hline \multicolumn{8}{|c|}{ T. Bilirubin (mg/dL) } \\
\hline mean \pm S.E. & $0.45 \pm 0.06$ & $2.51 \pm 0.18$ & $0.58 \pm 0.06$ & $1.05 \pm 0.07$ & & & \\
\hline $\mathrm{t}$ & & -11.03 & -1.52 & -6.17 & 10.42 & 7.65 & -4.98 \\
\hline$P$ & & $<0.001$ & $>0.05$ & $<0.001$ & $<0.001$ & $<0.001$ & $<0.001$ \\
\hline
\end{tabular}

$\mathrm{P}>0.05$ : non-significant difference; $\mathrm{P}<0.05$ : significant difference; $\mathrm{P}<0.01$ and $\mathrm{P}<0.001$ : highly significant difference

Table 4

Analysis of variance (ANOVA)

\begin{tabular}{|c|c|c|c|c|c|}
\hline & $\begin{array}{c}\text { CRF } \\
\text { (mean) }\end{array}$ & $\begin{array}{c}\mathrm{LC} \\
\text { (mean) }\end{array}$ & $\begin{array}{c}\text { CRF/LC } \\
\text { (mean) }\end{array}$ & $\begin{array}{c}\text { Fisher's-ratio } \\
\text { (F-ratio) }\end{array}$ & $P$ \\
\hline Creatinine & 12.75 & 0.73 & 9.30 & 151.090 & $<0.001$ \\
\hline $\mathrm{Lp}(\mathrm{a})$ & 87.25 & 11.10 & 24.65 & 115.115 & $<0.001$ \\
\hline EPO & 6.21 & 22.70 & 4.32 & 89.736 & $<0.001$ \\
\hline T. Bilirubin & 0.58 & 1.05 & 2.51 & 76.266 & $<0.001$ \\
\hline Cholesterol & 241.95 & 137.20 & 130.30 & 66.801 & $<0.001$ \\
\hline ALT & 11.80 & 35.20 & 51.15 & 59.999 & $<0.001$ \\
\hline $\mathrm{AST}$ & 14.15 & 50.85 & 62.65 & 53.80 & $<0.001$ \\
\hline BUN & 86.45 & 10.0 & 58.80 & 48.504 & $<0.001$ \\
\hline Age & 52.40 & 52.40 & 51.95 & 0.019 & $>0.05$ \\
\hline
\end{tabular}

latter group showed non-significantly different levels from the controls $(\mathrm{P}>0.05)$, with no significant difference between the atherosclerotic and non-atherosclerotic subjects as well (Table 2).

Table 4 represents the different analysed parameters arranged in descending order according to their diagnostic importance in CRF and/or LC patients as revealed by ANOVA test.

\section{DISCUSSION}

Chronic renal failure (CRF) develops due to irreversible renal function deterioration as a consequence of destruction of over $80 \%$ of the nephrons. ESRD is finally reached when more than $90 \%$ of the nephrons have been destroyed, and the renal functions are impaired in such manner that is life-threatening. Regular dialysis 


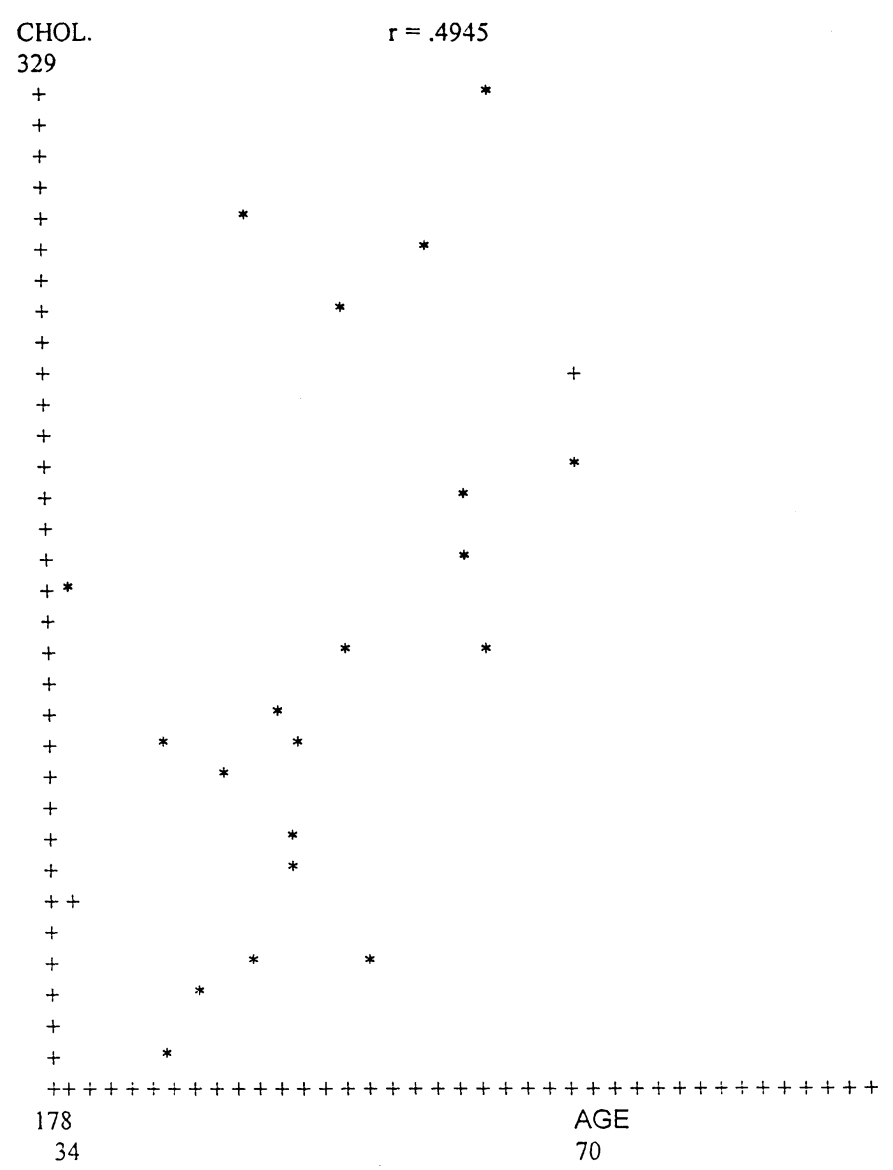

Fig. 1. Linear regression analysis showing the correlation between age and cholesterol in the CRF group.

is then essential to sustain life [20,21].

This study was constructed to investigate the functional state of the kidney and liver in CRF and/or LC patients, and the influence of each one on the other.

As the impaired function of the kidney and/or liver is manifested biochemically, association of both diseases together resulted in either intensification or amelioration of the biochemical changes.

On investigating the lipid parameters, the CRF subjects who had LC together with the LC subjects were found to have significantly reduced cholesterol levels compared with the controls $(\mathrm{P}<0.001)$ as a consequence of liver damage, while the CRF subjects without LC had significantly elevated cholesterol levels compared with the controls $(\mathrm{P}<0.01)$, and consequently with the two other patients groups ( $\mathrm{P}<0.001) .50 \%$ of the patients in this latter group were atherosclerotic, while none of the CRF subjects with LC was atherosclerotic. The atherosclerotic CRF subgroup showed a significant increase in cholesterol, $\mathrm{Lp}(\mathrm{a})$ and age compared to the non-atherosclerotic CRF patients ( $\mathrm{P}<0.001, \mathrm{P}<0.001$ and $\mathrm{P}<0.01$ respectively).

In 1974, Dahlen [23] first described an association between Lp(a) and CHD. Most studies on $\mathrm{Lp}(\mathrm{a})$ in chronically hemodialyzed patients with intact liver have reported significantly elevated Lp(a) levels in those patients, in agreement with our findings [1,5, 18,24-39]. Only some studies described $\mathrm{Lp}(\mathrm{a})$ values in $\mathrm{CRF}$ patients not significantly different from those in the controls [7,40-45]. However, in a recent study by Kronenberg et al. [46], which included 534 HD 


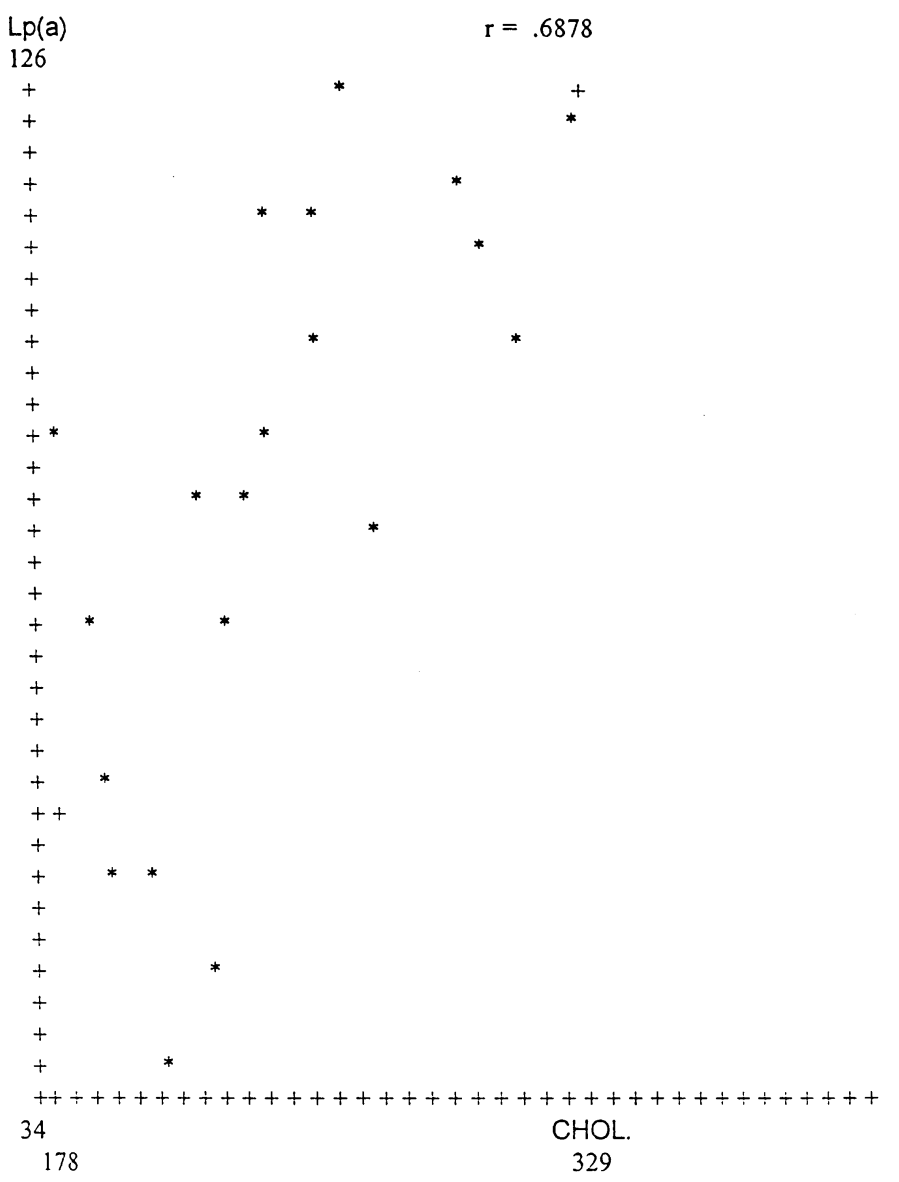

Fig. 2. Linear regression analysis showing the correlation between lipoprotein (a) and cholesterol in the CRF group.

patients, significantly elevated Lp(a) levels were found compared with the controls.

In the present study, CRF patients who did not have LC had mean Lp(a) level approximately 3.5 times higher than both the mean level of the control subjects and the assumed normal upper lineout of $30 \mathrm{mg} / \mathrm{ML}$. This agrees with two reports $[2,18]$ in which approximately 3-4 times higher Lp(a) levels were found in ESRD patients than in the normal controls.

The elevation observed in the atherosclerotic CRF subjects compared with the non-atherosclerotic ones in our study agrees with report of Cressman et al. [34] who found significantly higher Lp(a) levels (>73 mg/ ML) in HD patients with clinical events attributed to atherosclerosis than in those patients without such events. Also, Docci et al. [47] reported the presence of significantly higher mean Lp(a) level in HD patients with CHD than those without CHD, with lack of correlation between $\mathrm{Lp}(\mathrm{a})$ and cholesterol in the former group, although a significant positive correlation existed between both parameters when all the HD patients, with and without $\mathrm{CHD}$, were investigated as a single group, which agrees with the significant positive correlation we found between $\mathrm{Lp}(\mathrm{a})$ and cholesterol in CRF patients without LC. On the other hand, other investigators did not find this correlation in CRF patients $[16,18,41,48]$.

Hernandez et al. [49] confirmed the presence of higher $L p(a)$ levels in HD patients with failure of vascular access than those without failure of vascular access, but this difference did not reach a statistical significance. These authors reported lower vascular access survival in patients with 
Lp(a) between 50 and $75 \mathrm{mg} / \mathrm{dl}$ than those with $\mathrm{Lp}(\mathrm{a})<50 \mathrm{mg} / \mathrm{dl}$, but higher survival than patients with $\mathrm{Lp}(\mathrm{a})>75 \mathrm{mg} / \mathrm{dl}$. Several other studies, mostly with small patient groups, confirmed $L p(a)$ to be a risk factor for atherosclerotic alterations in ESRD, independent of alterations in other constituents [5-11]. Other studies were against Lp(a) establishment as an independent atherosclerotic risk factor $[25,30,37,50]$. However, a recent study by Ritz [51] held strong evidence for the atherosclerotic role of $\operatorname{Lp}(\mathrm{a})$, as this investigator found consistently higher levels of total cholesterol, low-density lipoprotein cholesterol (LDL-C), apoB and other coronary risk indicators except $L p(a)$ in survivor HD patients than in those dying from cardiovascular causes.

Nearly every study that reported elevated $\mathrm{Lp}$ (a) levels in renal disease, whether in favor of or against the idea of $L p(a)$ atherogenicity, suggested a role of the kidney in $L p(a)$ metabolism. Elevated Lp(a) level in CRF was suggested to be of non-genetic origin and secondary to the renal disease. This is consistent with the normalization in $\mathrm{Lp}$ (a) levels following renal transplantation, which also argues against an elevation induced by an acute phase reaction in ESRD [51-55].

Two explanations have been suggested for Lp(a) elevation in CRF [32]. First, the kidney might have an indirect influence on $\operatorname{Lp}(\mathrm{a})$ synthesis in the liver, probably through a factor that is secreted by the kidney and regulates $L p(a)$ synthesis. The second explanation is that the kidney may have a direct metabolic function, and degrades $L p(a)$, since various renal cell types express the LDL receptor-related protein believed to play a role in $\mathrm{Lp}$ (a) catabolism [54]. Also, the kidney with its dense capillary network provides an imposing endothelial surface. Due to the high homology between apo(a) and plasminogen, a high density of plasminogen receptors is also available for apo(a) [55]. Impairment of these receptor systems in CRF might also influence the regulatory mechanisms of the hepatic synthesis and/or catabolic sites. Although some investigators are in favor of attributing the control of $\mathrm{Lp}(\mathrm{a})$ levels to increased hepatic production induced by proteinuria $[41,56]$. This route could only be valid in patients undergoing continuous ambulatory peritoneal dialysis (CAPD), as HD patients hardly suffer from any substantial protein loss [1].

In our study, we found significantly reduced $\mathrm{Lp}$ (a) levels in LC patients. This finding agrees with other reports [1,57-60]. The two contradictory mechanisms of CRF and LC influencing $\mathrm{Lp}$ (a) plasma level counterpoised in the patients investigated in this study that had both diseases. Consequently, those patients showed apparently normal $L p(a)$ levels although normal $L p(a)$ metabolism was not maintained in them.

In CRF patients with and without LC, BUN and creatinine levels increased significantly as a result of the impaired excretory function of the failed kidneys in those patients, while in LC patients BUN levels decreased significantly due to impaired urea formation by the cirrhotic liver. Although the CRF subjects with LC had elevated BUN and creatinine levels, BUN levels were significantly lower than those of the CRF subjects without LC, due to the combined effect of both CRF and LC together, yet exerting opposite influence on BUN level i.e., LC causing reduced hepatic synthesis of urea while CRF reducing urea excretion resulting in elevation of BUN level relative to the urea initially synthesized by the cirrhotic liver. As a result, those patients had significantly lower BUN levels than those with CRF only $(\mathrm{P}<0.001)$. However, the role of the kidney in this case was more pronounced than that of the liver. This is confirmed by the positive significant correlation that was found between BUN and creatinine in both CRF groups.

Concerning the liver function in the studied groups, the highest significant elevations in ALT, AST, and bilirubin were always found in LC and CRF with LC groups. However, CRF with LC showed a significant increase over LC alone in the three parameters $(\mathrm{P}<0.001, \mathrm{P}<0.05$ and $\mathrm{P}<0.001$ respectively) (Table 3). This implies that renal failure may have an influence in liver function on those patients.

The elevation that was found in ALP levels in CRF and in LC patients could attribute the 
extreme elevation that was found in the enzyme levels in the CRF subjects with LC to the association of both diseases together. These results are in accordance with those of Woitge et al. [22], who also found significantly increased ALP levels in CRF and in LC patients, and explained that the elevation found in $\mathrm{LC}$ was due to the release of the enzyme from the damaged hepatocytes into the plasma, however, the elevation observed in CRF was of non-hepatic origin, and may be due to increased bone turnover in those patients.

In this study, no correlation was found between $\mathrm{Lp}$ (a) and either age, or renal function in CRF patients, which agrees with the reports of other investigators who found no correlation between $\mathrm{Lp}(\mathrm{a})$ and either of these parameters in CRF patients $[1,16,18,61,62]$. Despite the significant positive correlation found in this study between $\mathrm{Lp}(\mathrm{a})$ and cholesterol in both CRF groups, the latter was positively correlated to age, while in both CRF groups Lp(a) was not correlated to age. These findings emphasize the role of $\mathrm{Lp}(\mathrm{a})$ as the primary, and independent, cause of atherosclerosis in the investigated CRF patients.

ANOVA test showed that, among the investigated parameters in CRF and/or LC patients, creatinine was the most important diagnostic marker according to its F-ratio, followed by $\mathrm{Lp}(\mathrm{a})$, total bilirubin, cholesterol, ALT, AST, BUN, and finally ALP.

\section{References}

[1] Dieplinger, H., Lackner, C., Kronenberg, F., Sandholzer, C., Lhotta, K., Hoppichler, F., Graf, H. and Konig, P. Elevated plasma concentrations of lipoprotein(a) in patients with end-stage renal disease are not related to the size polymorphism of apolipoprotein(a). J. Clin. Invest. 91, (1993) 397-401.

[2] Cressman, M.D., Abood, D., O’Neil, J. and Hoff, H.E. Lp(a) and premature mortality during chronic hemodialysis treatment. Chem. Phys. Lipids 67(8), (1994) 419-427.

[3] Tomlinson, J.E., McLean, J.W. and Lawn, R.M. Rhesus monkey apolipoprotein(a): sequence, evolution and site of synthesis. Biol. Chem. 264, (1989) 5957-5965.

[4] Seman, L.J., Jenner, A., McNamara, J.R. and Schaefer, E.J. Quantification of lipoprotein(a) in plasma by assaying cholesterol in lectin-bound plasma fraction. Clin. Chem. 40, (1994) 400403.

[5] Shoji, T., Nishizawa, Y., Nishitani, I.-L., Yamakawa, M. and Morii, H. High serum lipoprotein(a) concentrations in uremic patients tested with continuous ambulatory peritoneal dialysis. Clin. Nephrol. 38, (1992) 271-276.

[6] Del Cura, J., Gil-Paraiso, A., Borque, I., Carazo, M.E., Maside, C. and Sanchez-Casajus, A. Lipoprotein(a) in chronic renal failure patients undergoing hemodialysis: Does it have an independent role in the development of further cardiovascular complications? Nephron 65, (1993) 644-645.

[7] Docci, D., Baldrati, I., Capponcini, C. and Feletti, C. Serum lipoprotein(a) [Lp(a)] in hemodialysis patients. Nephrol. Dial. Transplant 9, (1994) 733-734.

[8] Kronenberg, F., Kathrein, H., Konig, P., Neyer, U., Sturm, W., Lhotta, K., Grochenig, E., Utermann, G. and Dieplinger, $\mathrm{H}$. Apolipoprotein(a) phenotypes predict the risk for carotid atherosclerosis in patients with end-stage renal disease. Arterioscler. Thromb. 14, (1994) 1405-1411.

[9] Kang, D.H., Lee, S.W., Kanig, S.W., Kim, H.S., Choi, K.H., Ha, S.K., Lee, H.Y. and Han, D.S. Lipoprotein(a) and ischemic heart disease in patients undergoing continuous ambulatory peritoneal dialysis (CAPD). Kidney Int. 47, (1995) 357.

[10] Wanner, C., Bartens, W., Walz, G., Nauck, M. and Schollmeyer, P. Protein loss and genetic polymorphism of apolipoprotein(a) modulate serum lipoprotein(a) in CAPD patients. Nephrol. Dial. Transplant 10, (1995) 75-81.

[11] Webb, A.T., Reavely, D.A., O’Donnell, M., O'Connor, B., Seed, M. and Brown, E.A. Lipids and lipoprotein(a) as risk factors for vascular disease in patients on renal replacement therapy. Nephrol. Dial. Transplant 10, (1995) 354-357.

[12] Utermann, G. The mysteries of lipoprotein(a). Science 246, (1989) 904-910.

[13] Albers, J.J., Marcovina, S.M. and Lodge, M.S. The unique lipoprotein(a): properties and immunochemical measurement. Clin. Chem. 36, (1990) 2019-2026.

[14] Armstrong, V.W., Cremer, D., Eberle, E., 
Marke, A., Schulze, F. and Wieland, H. The association between serum $\mathrm{Lp}$ (a) concentrations and angiographically assessed coronary atherosclerosis: Dependence on serum LDL levels. Atherosclerosis 62, (1986) 249-257.

[15] Hoefler, G., Harnoncourt, F., Paschke, E., Mirth, W., Pfeiffer, K.H. and Kostner, G.M. Lipoprotein $\mathrm{Lp}(\mathrm{a})$ : A risk factor for myocardial infarction. Arteriosclerosis 8, (1988) 398-401.

[16] Genest, J. Jr., Jenner, A., McNamara, J.R., Ordovas, J.K., Silberman, S.R., Wilson, P.W.F. and Schaefer, E.J. Prevalence of lipoprotein(a) [Lp(a)] excess in coronary artery disease. Am. J. Cardiol. 15, (1991) 1039-1045.

[17] Rosengren, A., Wilhelmsen, I., Ericksson, E., Risberg, B. and Wedel, H. Lipoprotein(a) and coronary heart disease. A prospective casecontrol study in a population of middle-aged men. Br. Med. J. 301, (1992) 1248-1251.

[18] Parra, H.J., Mezdour, H., Cachera, C., Dracon, M., Tacquet, A. and Fruchart, J.C. Lp(a) lipoprotein in patients with chronic renal failure treated by hemodialysis. Clin. Chem. 33, (1987) 721.

[19] Labeur, C., Michiels, G., Bury, J., Usher, D.C. and Rosseneu, M. Lipoprotein(a) quantified by an enzyme-linked immunosorbent assay with monoclonal antibodies. Clin. Chem. 35, (1989) 13804.

[20] Mayne, P.D. (ed.) The kidneys and renal calculi. In: Clinical Chemistry in Diagnosis and Treatment. Weatherall, Ledingham and Warrell, Oxford University Press, Oxford (1994) 1-24.

[21] Goldfarb, S. and Ziyadeh, F. Renal diseases and fluid and electrolyte disorders. In: Medicine. Myers, A.R. (ed.) N.M.S., Williams \& Wilkins, Waverly Int, USA (1997) 279-321.

[22] Woitge, H.W., Seibel, M.J. and Ziegler, R. Comparison of total and bone-specific alkaline phosphatase in patients with non-skeletal disorders of metabolic bone diseases. Clin. Chem. 42, (1996) 1796-1804.

[23] Dahlen, G. The pre-beta I lipoprotein phenomenon in relation to serum cholesterol and triglyceride levels, the $\mathrm{Lp}$ (a) lipoprotein and coronary heart disease. Acta Mod. Scand. Suppl. 570, (1974) 1-45.

[24] Haffner, S.M., Gruber, K.Y., Aldrete, G. Jr., Morales, P.A., Stem, M.P. and Tuttle, K.R. Increased lipoprotein(a) concentrations in chronic renal failure. J. Am. Soc. Nephrol. 3(5), (1992) 1156-1162.

[25] Parsy, D., Dracon, M., Cachera, C., Parra, H.J.,
Vanhoutte, G., Tacquat, A. and Fruchart, J.C. Lipoprotein abnormalities in chronic hemodialysis patients. Nephrol. Dial. Transplant 3, (1988) 51-56.

[26] Heimann, P., Josephson, M.A., Fellner, S.K., Thistlethwaite, J.R., Stuart, F.P. and Dasgupta, A. Elevated lipoprotein(a) levels in renal transplantation and hemodialysis patients. Am. J. Nephrol. 11, (1991) 470-474.

[27] Barbagallo, C.K., Averna, M.R., Scafidi, V., Galione, A. and Notarbartolo, A. Increased lipoprotein(a) levels in subjects with chronic renal failure on hemodialysis. Nephron 62, (1992) 471-472.

[28] Cressman, M.D., Heyka, R.J., Paganini, E.P., O’Neil, J., Skibinski, C.L. and Hoff, H.F. Lipoprotein(a) is an independent risk factor for cardiovascular disease in hemodialysis patients. Circulation 86, (1992) 475-482.

[29] Kandoussi, A., Cachera, C., Pagrniez, D., Dracon, M., Fruchart, J.C. and Tacquat, A. Plasma level of $\mathrm{Lp}$ (a) lipoprotein is high in predialysis or hemodialysis, but not in CAPD. Kidney Int. 42, (1992) 424-425.

[30] Auguet, T., Senti, M., Rubies-Part, J., Pelegri, A., Pedro-Botet, J., Nogues, X. and Romero, R. Serum lipoprotein(a) concentration in patients with chronic renal failure receiving hemodialysis: Influence of apolipoprotein(a) genetic polymorphism. Nephrol. Dial. Transplant (1993) 8(10), 1099-1103.

[31] Barbagallo, C.M., Averna, M.R., Sparacino, V., Galione, A., Caputo, F., Scafidi, V., Amato, S., Mancino, C., Cefalu, A.B. and Notarbartolo, A. Lipoprotein(a) levels in end-stage renal failure and renal transplantation. Nephron 64, (1993) 560-564.

[32] Hirata, K., Kikuchi, S., Saku, K., Jimi, S., Zhang, B., Naito, S., Hamaguchi, H. and Arakawa, K. Apolipoprotein (a) phenotypes and serum lipoprotein(a) levels in maintenance hemodialysis patients with/without diabetes mellitus. Kidney Int. 44, (1993) 1062-1070.

[33] Okura, Y., Saku, K., Hirata, K., Zhang, B., Liu, R., Ogahara, S., Naito, S., Kajiyama, G. and Arakawa, K. Serum lipoprotein(a) levels in maintenance hemodialysis patients. Nephron $\mathbf{6 5}$, (1993) 46-50.

[34] Webb, A.T., Reaveley, D.A., O’Donnell, M., O'Connor, B., Seed, M. and Brown, E.A. Lipoprotein(a) in patients on maintenance hemodialysis and continuous ambulatory peritoneal dialysis. Nephrol. Dial. Transplant 8, 
(1993) 609-613.

[35] Suleymanlar, G., Ozben, T., Sapan, M., Yalmaz, H., Ersoy, F. and Yakupoglu, G. Serum lipoprotein(a) changes in patients with chronic renal failure on dialysis (HD or CAPD). Nephrol. Dial. Transplant 9, (1994) 1026.

[36] Fiorini, F., Masturzo, P., Mij, M. and Bertolini, S. Lipoprotein(a) levels in hemodialysis patients: Relation to glucose intolerance and hemodialysis duration. Nephron 70, (1995) 500-501.

[37] Gault, M.H., Longerich, L.I., Purchase, I., Harnett, J. and Breckenridge, C. Comparison of $\mathrm{Lp}$ (a) concentrations and some potential effects in hemodialysis, CAPD, transplantation, and control groups, and review of the literature. Nephron 70, (1995) 155-170.

[38] Joven, J., Simo, A., Vilella, E., Camps, J., Espinel, E. and Villabona, C. Accumulation of atherogenic, remnants and lipoprotein(a) in the nephrotic syndrome: relation to remission of proteinuria. Clin. Chem. 41, (1995) 908-909.

[39] Kronenberg, F., Konig, P., Neyer, U., Auinger, M., Pribasnig, A., Lang, U., Reitinger, J., Pinter, G., Utermann, O. and Dieplinger, H. Multicenter study of lipoprotein(a) and apolipoprotein(a) phenotypes in patients with end-stage renal disease treated by hemodialysis or continuous ambulatory peritoneal dialysis. J. Am. Soc. Nephrol. 6, (1995) 110-120.

[40] Irish, A.B., Hayes, J.M., Simons, L.A., Simons, J. and Savdie, E. Lipoprotein(a) levels in chronic renal disease states, dialysis and transplantation. Aust. N.-Z. J. Med. 22, (1992) 243-248.

[41] Buggy, D., Breathnach, A., Keogh, B., Cooke, T. and Feely, J. Lipoprotein(a) and treatment of chronic renal disease. J. Intern. Med. 234(5), (1993) 453-455.

[42] Querfeld, U., Lang, I., Friedrich, J.B., Kohl, B., Fiehm, W. and Scharer, K. Lipoprotein(a) serum levels and apolipoprotein(a) phenotypes in children with chronic renal disease. Pediatr. Res. 34, (1993) 772-776.

[43] Oymak, O., Erdem, Y., Yasavul, U., Turgan, C., Caglar, M., Bakkaloglu, M. and Caglar, S. Lipoprotein(a) levels in hemodialysis and renal transplant patients. Nephrol. Dial. Transplant 9, (1994) 1054-1055.

[44] Heimburger, O., Stenvinkel, P., Berglund, L., Tranoeus, A. and Lindholm, B. Increased plasma lipoprotein(a) in continuous ambulatory peritoneal dialysis is related to peritoneal transport of proteins and glucose. Nephron 72(2), (1996) 135-144.
[45] De Lima, J.J., Maranhao, R.C., Latrilha, M., Diament, J., Romao, J.E., Krieger, E.M. and Pileggi, F. Early elevation of lipoprotein(a) levels in chronic renal insufficiency. Ren. Fail. 19(1), (1997) 145-154.

[46] Kronenberg, F., Utermann, G. and Dieplinger, H. Lipoprotein(a) in renal disease. Am. J. Kidney Dis. 27, (1996) 1-25.

[47] Docei, D., Manzoni, G., Bilancioni, R., Delveccehio, C., Capponcini, C., Baldrati, L., Neri, L. and Feletti, C. Serum lipoprotein(a) and coronary artery disease in uremic patients on chronic hemodialysis. Int. J. Artif. Organs 17(1), (1994) 41-45.

[48] Karadi, I., Romics, L., Palos, O., Doman, J., Kaszas, I., Hesz, A. and Kostner, G.M. Lp(a) lipoprotein concentration in serum of patients with heavy proteinuria of different origin. Clin. Chem. 35, (1989) 2121-2123.

[49] Hernandez, E., Prage, M., Alamo, C., Araque, A., Morales, J.M., Alcazar, J.M., Ruilope, L.M. and Rodicio, J.L. Lipoprotein(a) and vascular access survival in patients on chronic hemodialysis. Nephron 72(2), (1996) 145-149.

[50] Goldwasser, P., Michel, M.-A., Collier, J., Mittman, N., Fein, P.A., Gusik, S.A. and Avram, M.M. Pre-albumin and lipoprotein(a) in hemodialysis: Relationships with patient and vascular access survival. Am. J. Kidney Dis. 22, (1993) 215-225.

[51] Ritz, E. Why are lipids not predictive of cardiovascular death in the dialysis patients? Miner Electrolyte Metab. 22(1-3), (1996) 9-12.

[52] Black, I.W. and Wilcken, D.E.L. Decrease in apolipoprotein(a) after renal transplantation: Implications for lipoprotein(a) metabolism. Clin. Chem. 38, (1992) 353-357.

[53] Kronenberg, F., Konig, P., Lhotta, Y., Ofner, D., Sandholzer, C., Margreiter, I., Dosch, E., Utermarm, G. and Dieplinger, H. Apolipoprotein(a) phenotype-associated decrease in lipoprotein(a) plasma concentrations after renal transplantation. Arterioscler. Thromb. 14(9), (1994) 1399-1404.

[54] Marz, W., Beckmann, A., Scharnagl, H., Siekmeier, R., Mondorf, U., Held, I., Schneider, W., Preissner, K.T., Curtis, L.K., Gross, W. and Huttinger, M. Heterogeneous lipoprotein(a) size isoforms differ by their interaction with the low density lipoprotein receptor and the law density lipoprotein receptor-related protein $/ \mathrm{a}_{2}$-macroglobulin receptor. FEBS 325, (1993) 271-275.

[55] Gonzalez-Gronow, M., Edelberg, J.K. and Pizzo, 
S.V. Further characterization of the cellular plasminogen binding site: Evidence that plasminogen 2 and lipoprotein(a) compete for the same site. Biochemistry 28, (1989) 23742377.

[56] Rader, D.J., Cain, W., Zech, L.A., Usher, D. and Brewer, H.B. Jr., Variation in lipoprotein(a) concentrations among individuals with the same apolipoprotein(a) isoform is determined by the rate of lipoprotein(a) production. J. Clin. Invest. 91, (1993) 443-447.

[57] Feely, J., Barry, M., Keeling, P.W.N., Weir, D.G. and Cooke, T. Lipoprotein(a) in cirrhosis. Br. Mod. J. 304, (1992) 545-546.

[58] Alessandri, C., Basili, S., Maurelli, M., Andreozzi, P., Violi, F. and Cordova, C. Relationship between lipoprotein(a) levels in serum and some indices of protein synthesis in liver cirrhosis. [Abstract] Clin. Chem. Acta 31
224(2), (1994) 125-129.

[59] Gregory, W.L., Game, F.L., Farrer, M., Idle, J.R., Laker, M.F. and James, O.F.W. Reduced serum lipoprotein(a) levels in patients with primary biliary cirrhosis. Atherosclerosis 105, (1994) 43-50.

[60] Van Wersch, J.W. The behavior of lipoprotein(a) in patients with various diseases. Scand. J. Clin. Lab. Invest. 54(7), (1994) 559-562.

[61] Albers, J.J. and Hazzard, W.R. Immunochemical quantification of human plasma $\mathrm{Lp}(\mathrm{a})$ lipoprotein. Lipids 9, (1974) 15-26.

[62] Oida, K., Takai, H., Maeda, H., Takahashi, S., Shimada, A., Suzuki, J., Tamai, T., Nakaki, T. and Miyabo, S. Apolipoprotein(a) is present in urine and its excretion is decreased in patients with renal failure. Clin. Chem. 38, (1992) 22442248 . 


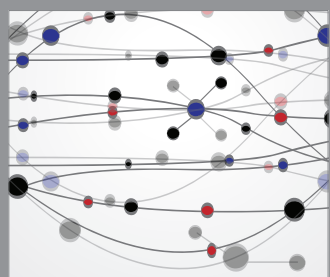

The Scientific World Journal
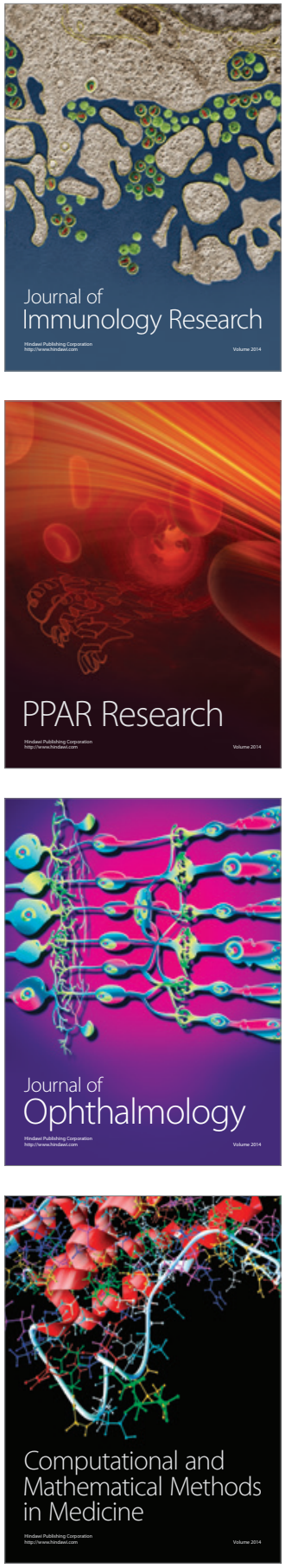

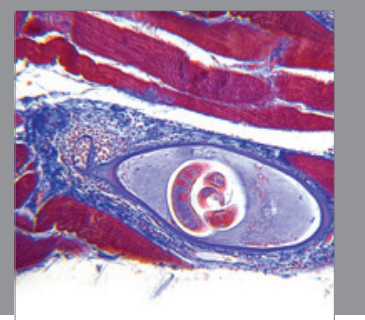

Gastroenterology

Research and Practice
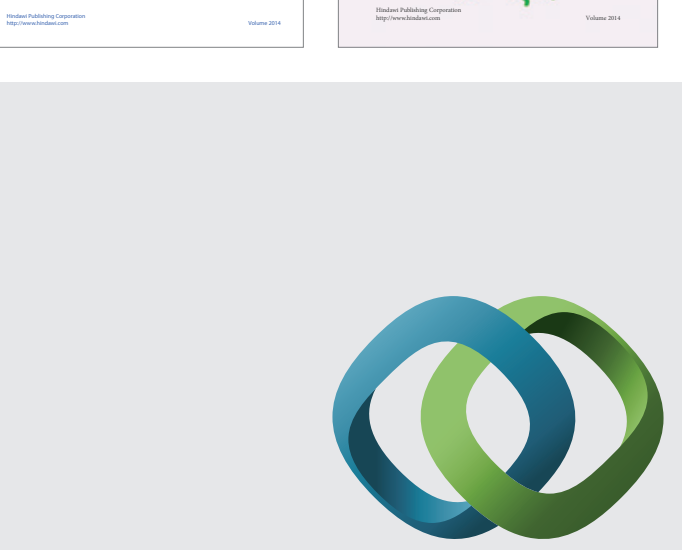

\section{Hindawi}

Submit your manuscripts at

http://www.hindawi.com
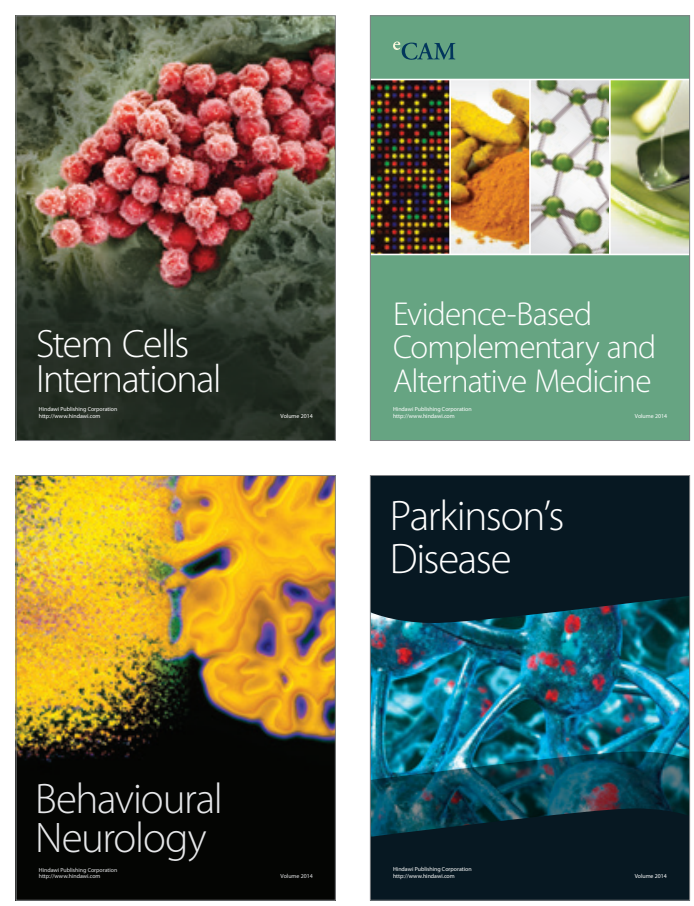

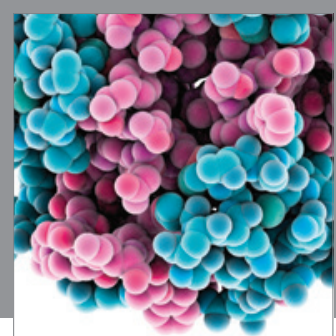

Journal of
Diabetes Research

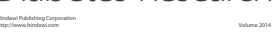

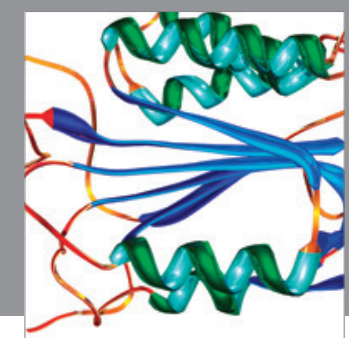

Disease Markers
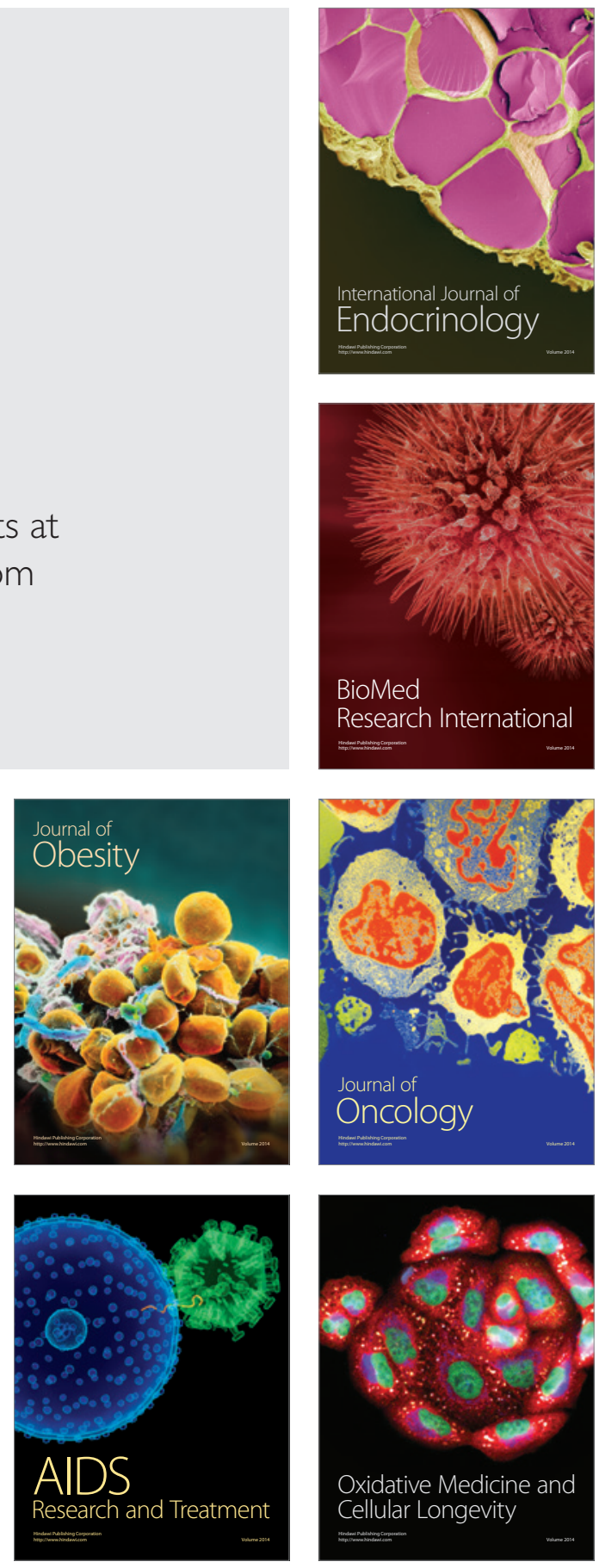